\title{
USE OF WAVELET TECHNIQUES IN THE STUDY OF INTERNET MARKETING METRICS
}

\author{
Murad OMAROV ${ }^{1, *}$, Tatyana TIKHAYA ${ }^{1}$, Vyacheslav LYASHENKO² \\ ${ }^{1}$ Department of Natural Science, Kharkiv National University of RadioElectronics, Kharkiv, Ukraine \\ ${ }^{2}$ Department of Informatics, Kharkiv National University of RadioElectronics, Kharkiv, Ukraine
}

\begin{abstract}
Generalized set of classic metrics for evaluating internet marketing. Existing approaches to analyzing Internet marketing metrics have been noted. The application of the wavelet analysis technique for the study of Internet marketing metrics is proposed. Wavelet coherence was chosen to unveil the ideology of using wavelet analysis techniques to study Internet marketing metrics. A comparative analysis of Internet marketing metrics on different queries based on wavelet coherence is revealed. The merits of using a coherence wavelet are exemplified by an example of a basic internet marketing metric - clicks per request. The possibility of visual analysis of Internet marketing metrics using wavelet analysis technique was noted. Specific examples of the use of coherence wavelet for analyzing Internet marketing on specific queries are given.
\end{abstract}

Keywords: Wavelet coherence, Internet marketing, Click, Internet metrics

\section{INTRODUCTION}

Internet marketing is one of the components of modern information means, which plays an important role both in terms of forming new economic relationships, and taking into account the effectiveness of the use of the latest technologies in different spheres of life of an individual, the functioning of economic entities, the development of society. This is determined by the fact that the main task of Internet marketing is to ensure the search for various offers (goods, services, etc.), meet the needs of potential consumers, cover the costs of manufacturers, suppliers of various services.

At the same time, the development of Internet marketing can be implemented according to conceptual bases of information systems functioning [1]. Therefore, Internet marketing is also a platform for the introduction of the latest information technologies. At the same time, various indicators are of great importance among the key principles of the functioning of Internet marketing as an information system, which determine the effectiveness of its implementation.

It is possible to distinguish such characteristics as: number of conversions (site visits), most used search phrases, time spent on search, length of site visit, etc. [2]. Therefore, such statistics can be the basis for both generalizing the assessment and making new management decisions regarding the functioning and development of modern Internet marketing systems.

One of the key issues in the processing of statistics is the use of modern methods of processing them, which allow to clearly show trends not only in the formation of such data, but also to determine the relationship between the relevant aggregate characteristics of Internet marketing. The disclosure of this question determines the main purpose of this study.

*Corresponding Author: tikhusya@gmail.com

Received: 13.10.2019 Published: 16.12.2019 


\section{MATERIALS AND METHODS}

\subsection{Brief Literature Review}

The statistical characteristics of Internet marketing include a number of different metrics.

For example, J.R. Saura, P.Palos-Sanche and L.M. Cerda Suarez is one of the most significant indicators of Internet marketing comparing the costs of conducting a separate Internet marketing line to the revenue generated from such activities and the number of clicks that are relevant to the individual product (offers) [3]. G. D. Gregory, L. V. Ngo, and M. Karavdic also hold the same opinion [4], Y. Y. K. Chen, Y. L. Jaw, B. L. Wu [5].

Along with this, among the Internet marketing indicators also allocate the so-called cost per click, respectively, as the ratio of revenue received to the number of clicks according to the selected group of offers (goods, services, etc.) [6,7].

Equally important is the overall dynamic of clicks on the search for a particular offer item over a period of time. Particular attention to this indicator can be found in the studies of J.R. Saura, P.Palos-Sanche and L.M. Cerda Suarez [3], J. Jarvinen, H. Karjaluoto [6], S. Ainin, F. Parveen, S. Moghavvemi, N. I. Jaafar, N. L. Mohd Shuib [8], N. Anand, N. Grover [9]. The importance of such an indicator is determined by the fact that it is the basis for determining other characteristics of Internet marketing. That is, such an indicator can be considered as a baseline in revealing the effectiveness and efficiency of Internet marketing. Other metrics are derived from the Internet marketing benchmark.

It should also be noted that, typically, a basic internet marketing metric is a series of values (clicks) over a period of time. So we have some time series that are used to calculate other metrics for evaluating internet marketing. That is, we can also point out that, based on a certain period of time, you can specify a number of derivatives that determine certain characteristics of Internet marketing. Therefore, derivatives can also be considered as a specific time series.

Therefore, as described above, descriptive and analytical statistics should be included in the main dataprocessing toolkit, which is a variety of internet marketing metrics. In particular, this apparatus is used in their research, for example, C. S. Katsikeas, N. A. Morgan, L. C. Leonidou, G. T. M. Hult [10], P. Farris, N. Bendle, P. Pfeifer, D. Reibstein [11].

At the same time, neural network theory, factor analysis, optimization theory, etc. are also used for more complex analysis $[8,11,12]$.

However, in our opinion, these approaches to determining the assessment of Internet marketing do not sufficiently take into account the possible manifestations of influences in terms of finding related offers (goods, services, etc.) and related queries. Also lacking is a visualization component of relevant analysis that provides additional information for decision making. To a certain extent, solving the problem is helped by the application of the wavelet theory, which has good reviews on the application in various information systems [13-15].

\subsection{Wavelet Analysis as a Research Tool}

Wavelet theory aims at processing data that can be represented, in particular, as a certain sequence of data. In particular, such data can be reported as a time series. Then, using wavelet analysis, one can find the individual characteristic points of the time series under study [15]. So we get a set of new timeline features that expands the horizons of analysis. That is, the new characteristics are distinguished by the 
fact that they make the initial significance for certain segments (within different characteristics) of the time series under study. Therefore, this data is additional information for drawing conclusions, and in particular in terms of determining the effectiveness of Internet marketing implementation

Among the wavelet analysis tools, the so-called wavelet coherence draws particular attention $[16,17]$. At the same time the mutual dynamics of two time series is analyzed. Thus, the use of wavelet coherence allows to analyze the consistency and balance of the determined dynamics from the studied data. The basis for implementing the coherence wavelet is the analysis of cross-links between the time series of the data being investigated. That is, as a result, we obtain a matrix of local correlations of two time series, which determines the possibility of visualizing the effects in the mutual dynamics for the studied series.

To implement the coherence wavelet, a formalized model is used as an analysis tool wavelet coherence as the squared absolute value of the smoothed cross wavelet spectra $W_{x y}(f, q)$ for different time series $f$ and $q$, ( $\mathrm{x}$ - first variable and $\mathrm{y}$ - second variable of the data time series. Usually $\mathrm{x}$ is a location parameter, $y$ is a scale parameter that are determined by maternal wavelet, normalized by the product of the smoothed individual wavelet power spectra of each series $[16,17]$ :

$$
\mathrm{R}^{2}(\mathrm{f}, \mathrm{q})=\frac{\left|\mathrm{Q}\left(\mathrm{q}^{-1} \mathrm{~W}_{\mathrm{xy}}(\mathrm{f}, \mathrm{q})\right)\right|}{\mathrm{Q}\left(\mathrm{q}^{-1}\left|\mathrm{~W}_{\mathrm{x}}(\mathrm{f}, \mathrm{q})\right|^{2}\right) \mathrm{Q}\left(\mathrm{q}^{-1} \mid \mathrm{W}_{\mathrm{y}}\left(\mathrm{f},\left.\mathrm{q}\right|^{2}\right)\right.},
$$

where $\mathrm{Q}$ - is a smoothing operator.

Morlet wavelet that is a complex wavelet with a good time-frequency localization is used as the mother wavelet $[16,17]$.

The squared wavelet coherency coefficient is in the range $0 \leq \mathrm{R}^{2}(\mathrm{u}, \mathrm{s}) \leq 1$, a value close to zero indicates weak correlation, while values close to one are evidence of strong correlation.

Thus, wavelet coherency allows you to analyze the interconnection between the studied series over time and to analyze the frequency of occurrence of such a connection.

\subsection{Data for the Analysis}

In order to prove the feasibility of applying a wavelet coherence methodology to recognize the evaluation of Internet marketing, we consider two queries as an example: shoes and sandals. These inquiries reveal the interest of potential customers in purchasing relevant products. However, as a metric for the selected queries, you can consider the so-called dynamics of the popularity of the query over a period of time. That is, for each defined date in the selected time interval, the relevant popularity of the query is determined by a certain level of interest in that query. In particular, 100 points is the highest level of interest, 50 points is the level of interest (and therefore the availability of queries) is twice less than the level of 100 points, 0 points is the lack of interest (in other words, there are no queries).

In "Figure" (Figure 1) shows the corresponding dynamics of interest levels on the request of "shoes" and "sandals" in the whole of Ukraine for the next 90 days starting from 05.06.2019 (in total we have 91 values). Data taken from the site https://trends.google.com.ua. 


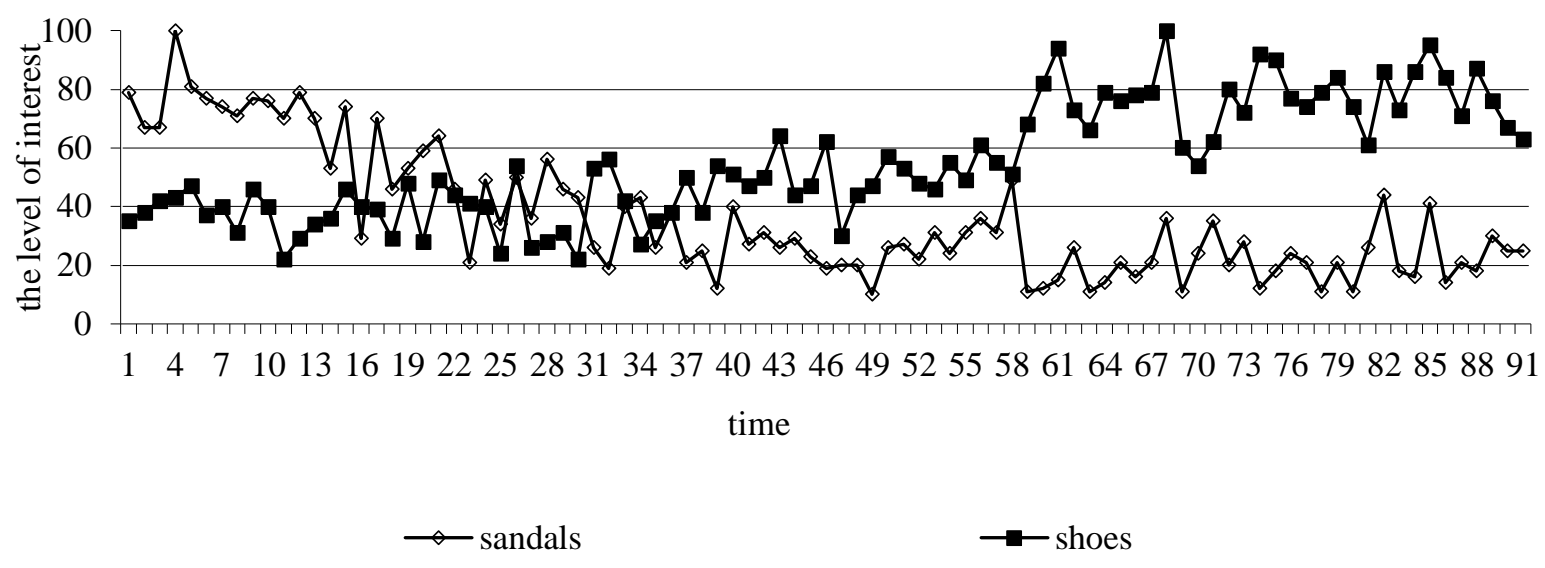

Figure 1. Dynamics of the level of interest on the request of "shoes" and "sandals"

From "Figure" (Figure 1) it is clear that the dynamics in the context of individual requests is quite different. Therefore, comparing such dynamics with each other causes some interest. First of all, such an interest can be formulated through the question - are there any reciprocal influences between the queries based on the time period studied? In particular, from the point of view of Internet marketing, such a question allows to determine the limits of its correction with respect to further management in view of the possible impact of one request on another, and thus the corresponding flow of potential customers between different types of goods.

\section{RESULTS AND DISCUSSION}

According to the above in "Figure" (Figure 2) presents the results of the wavelet sequence between data rows reflecting the level of interest in the request for "shoes" and "sandals" (according to the data shown in "Figure" (Figure 1)).

The abscissa axis "Figure" (Figure 2) shows the time scale, which corresponds to the sequence of analyzed data based on the selected time period. Such a sequence coincides with the selected time periods according to "Figure" (Figure 1).

The ordinate axis "Figure" (Figure 2) shows the weighted characteristic of the analyzed data series in the frequency space of their measurement by the results of the grouped time periods according to the total time interval. That is, this characteristic defines certain successive steps taken to determine the individual values of wavelet coherence.

The dotted line in "Figure" (Figure 2) in the form of an inverted parabola is the line of reliability of the received calculations. In the middle of such parabola, the accuracy of the obtained calculations is $0.95 \%$. These calculations are based on the Monte Carlo method [16, 17].

A column is also shown along the figure as a scale for the wavelet coherence displayed on the common matrix. Separate areas are the localization of the manifestations of homogeneities or inhomogeneities in the individual time series studied according to their importance. In general, each point of the wavelet mapping is presented the time series under study are their wavelet coherence values calculated by wavelet transform. 


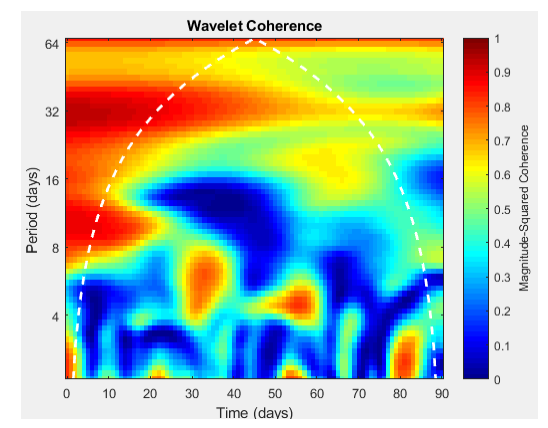

Figure 2. Wavelet coherence between data rows that reflect the level of interest in "shoes" and "sandals".

Therefore, from the data of "Figure" (Figure 2) shows that the dynamics between the requests for "shoes" and "sandals" by level of interest are generally diverse. However, there are also some times when the dynamics of interest between shoes and sandals match the level of interest. In particular, such a period, for example, is determined from 79 to 85 time interval or from 53 to 57 time interval (see data in "Figure" (Figure 2)). It should be noted that the dynamics between requests for "shoes" and "sandals", when the level of interest coincides, is longer and more stable in the period from 79 to 85 time intervals than in the period from 53 to 57 time interval. The basis for this conclusion is the more significant values for this period according to the $y$-axis.

Thus, it can be noted that the need to adjust the strategy for conducting Internet marketing in the marked periods of time, when the dynamics between the requests of "shoes" and "sandals" in terms of interest is more significant and significantly coincides. That is, in this case, it is important to use different online marketing tools to attract potential customers to your product offering.

We can also conduct an impact analysis of relevant requests based on a specific region of Ukraine. In this case, it is possible to analyze the significance of the dynamics by individual query according to a particular region.

In "Figure" (Figure 3) presents the wavelet coherence results between the series of data that reflect the level of interest in the "sandals" in the context of the whole of Ukraine and in the section of Kyiv ("Figure" (Figure 3a)), in the section of the whole of Ukraine and in the section of the Odessa region of Ukraine ("Figure" (Figure 3b)).

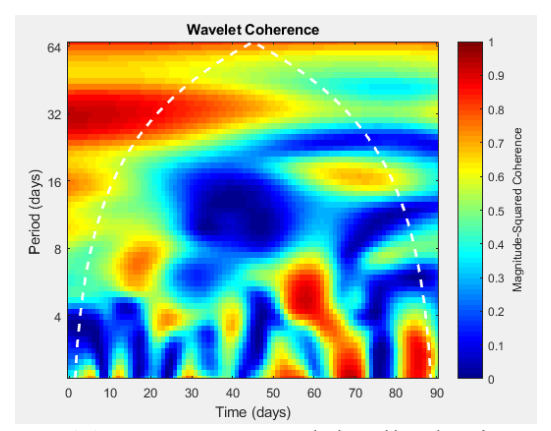

(a) request «sandals all Ukraine»«sandals Kyiv»

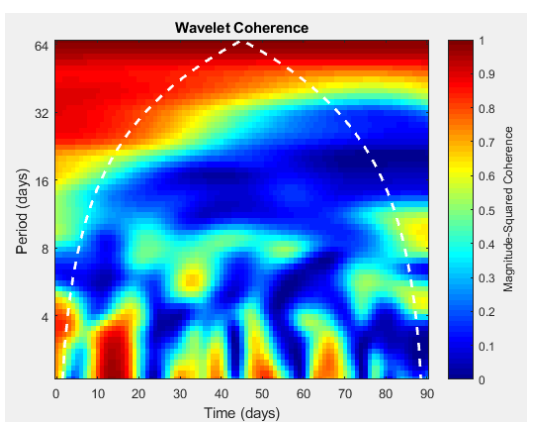

(b) request «sandals all Ukraine»«sandals Odessa region

Figure 3. Wavelet coherence between data rows that reflect the level of interest in the sandals by region of Ukraine. 
According to "Figure" (Figure 3), a significant difference can be observed between wavelet coherence for the request for sandals by region. Therefore, this allows you to differentiate between online marketing for different target audiences according to different time intervals.

\section{CONCLUSION}

The paper generalizes some metrics for Internet marketing. An Internet marketing benchmark has been identified that reveals the overall dynamics of possible clicks for a particular kind of query. Classical approaches to the application of methods of analysis of characteristics on conducting Internet marketing are also disclosed.

The application of the wavelet analysis technique for the study of Internet marketing metrics is proposed. Wavelet coherence is suggested as a separate wavelet analysis technique. The expediency of such introduction of the wavelet analysis technique is proved. Such expediency is determined by the possibility of conducting a thorough analysis in the context of individual queries, which has its logical explanation for determining the directions of Internet marketing for the selected queries. At the same time, the application of the Internet marketing metrics offered to the analysis makes it possible to visualize the dynamics between different queries, taking into account the levels of interest in such queries.

The results of the use of wavelet analysis technique for the study of Internet marketing metrics in the context of click dynamics for two specific queries.

\section{REFERENCES}

[1] Omarov M, Tikhaya T, Lyashenko V. Internet marketing technologies in civil engineering. Int J Civil Eng Tech 2018; 9: 1233-1240.

[2] Tsai YC, Cheng YT. Analyzing key performance indicators (KPIs) for E-commerce and Internet marketing of elderly products: A review. Arch Gero Geri 2012; 55(1): 126-132.

[3] Saura JR, Palos-Sanchez P, Cerda Suarez LM. Understanding the Digital Marketing Environment with KPIs and Web Analytics. Fut Int 2017; 9,76.

[4] Gregory GD, Ngo LV, Karavdic M. Developing e-commerce marketing capabilities and efficiencies for enhanced performance in business-to-business export ventures. Ind Market Managem 2017.

[5] Chen YYK, Jaw YL, Wu BL. Effect of digital transformation on organisational performance of SMEs: Evidence from the Taiwanese textile industry's web portal. Int Res 2016; 26(1): 186-212.

[6] Järvinen J, Karjaluoto $H$. The use of Web analytics for digital marketing performance measurement. Ind Market Manag 2015; 50, 117-127.

[7] Yang Z, Shi Y, Wang B. Search engine marketing, financing ability and firm performance in Ecommerce. Procedia Comput Sci 2015; 55, 1106-1112.

[8] Ainin S, Parveen F, Moghavvemi S, Jaafar NI, Mohd Shuib NL. Factors influencing the use of social media by SMEs and its performance outcomes. Ind Manag Data Syst 2015; 115(3), 570-588. 
[9] Anand N, Grover N. Measuring retail supply chain performance: Theoretical model using key performance indicators (KPIs). Benchmark Int J 2015; 22(1): 135-166.

[10] Katsikeas CS, Morgan NA, Leonidou LC, Hult GTM. Assessing performance outcomes in marketing. J Mark 2016; 80(2): 1-20.

[11] Farris P, Bendle N, Pfeifer P, Reibstein D. Marketing metrics: The manager's guide to measuring marketing performance. FT Press 2015.

[12] Phillips P, Zigan K, Silva MMS, Schegg R. The interactive effects of online reviews on the determinants of Swiss hotel performance: A neural network analysis. Tourism Man 2015; 50, 130 141.

[13] Tomás R, Li Z, Lopez-Sanchez JM, Liu P, Singleton A. Using wavelet tools to analyse seasonal variations from InSAR time-series data: a case study of the Huangtupo landslide. Lands 2016; 13, 437-450

[14] De Georgia MA, Kaffashi F, Jacono FJ, Loparo KA. Information technology in critical care: review of monitoring and data acquisition systems for patient care and research. Sci World J 2015.

[15] Dadkhah M, Lyashenko VV, Deineko ZV, Shamshirband S, Jazi MD. Methodology of wavelet analysis in research of dynamics of phishing attacks. Int J Advan Int Paradim 2019; 12(3-4): 220238.

[16] Torrence C, Webster PJ. Interdecadal changes in the ENSO-monsoon system. J Clim 1999; 12(8): 2679-2690.

[17] Grinsted A, Moore JC, Jevrejeva S. Application of the cross wavelet transform and wavelet coherence to geophysical time series. Nonlinear Process Geo 2004; 11(5/6): 561-566. 